For publication in Harris, A., Jones, M. and Huffman, J. (2017) Teachers Leading Educational

Reform: The Power of Professional Learning Communities. Abingdon: Routledge.

\title{
Teacher leadership within and across professional learning communities
}

\section{Louise Stoll, Chris Brown, Karen Spence-Thomas and Carol Taylor}

Teacher professionalism is fundamental to improving school quality. A call from the OECD for significant change in teachers' practice and development argues that education today demands "highlevel knowledge workers who constantly advance their own professional knowledge as well as that of their profession" (Istance and Vincent-Lancran, 2012, p36). Using evidence to find ways to enhance practice is an important feature of knowledge work. An expectation of collective responsibility also underlies this quote. Knowledge work has a collegial element - its purpose is not just for individual gain; it must enhance the profession as a whole. Systems internationally which sustain improvement are characterised by collaborative work and innovation (Mourshed et al, 2010), and a conclusion of TALIS 2013/14 (OECD, 2013) is that: "Countries could use professional development to effectively and efficiently build professional learning communities in schools".

In this chapter, we begin by exploring the context for professional learning communities within England. Then, we describe three relevant national projects which team members have led and some key findings. Finally, we conclude with four messages drawn from the projects about impactful teacher leadership of change and improvement within and across professional learning communities.

\section{England's policy context for professional learning communities}

The landscape of England's school system has shifted quickly over the last few years. An increasing international emphasis on collaboration (eg Schleicher, 2015) and peer networking (OECD, 2016) is seen in England in its policy focus on partnership working between schools to develop what has been described as a 'self-improving school system' (Hargreaves, 2010) - schools supporting each other's improvement. This has its origins in earlier New Labour government policy initiatives (DfEE, 1997; DfES, 2005). The previous Coalition government's policy White Paper (DfE, 2010) paved the way for school autonomy - with a fast-growing autonomous system where over $60 \%$ of secondary schools and $15 \%$ of primary schools are now academies or free schools, out of local authority control and directly responsible to national government. This was aligned to the policy intention for schools increasingly to collaborate through academy chains and multi-school trusts and federations. 
Increasingly, schools are connecting with each other, whether through formal or informal partnerships and networks. School-to-school support and peer-to-peer learning are viewed as important strategies to raise standards and improve the quality of teachers and school leadership - and Ofsted's ${ }^{1}$ framework inspects how effectively schools work in partnership.

With this policy emphasis, if teachers need to create and use knowledge to best effect and collaborate within and across schools to share knowledge, develop and deepen their practice, professional learning communities are a potentially powerful vehicle for change. To set our work in context, unlike some jurisdictions where they refer to small groups of teachers who come together at mandated times, the history of 'professional learning communities' in England - and the national research which introduced it (Bolam et al, 2005) - was of whole-school, collaborative, open, reflective and growthoriented cultures. In our own writing we see first and foremost, that members are purposeful; their goal is to make a positive difference to all students' learning experiences and outcomes now and for the future (Stoll et al, 2006). Such communities are inclusive, trusting, mutually supportive and collectively responsible for the learning of students and each other. Furthermore, they are endlessly curious, investigating and learning more about their practice together. Crucially, they deprivatize practice (Louis, Kruse et al, 1995) through reciprocal scrutiny and critical friendship. In TALIS's (OECD, 2013, p3) terms, professional learning communities are "developing the values, norms, and shared expectations". In a knowledge society, they also create, exchange and circulate knowledge (Stoll, 2015a; Brown et al., 2016). Generally an entire school staff would be described as a professional learning community while smaller numbers of teachers within a school more frequently are described as teacher learning communities (Wiliam, 2016). Cases also exist of cross-school professional learning communities - for example the Ealing Professional Learning Community (Stoll et al, 2012a), but learning communities that span more than one school usually go by other names, including network, partnership or alliance - and there are an increasing number of these in England. PLCs also need the structural architecture, within (Bolam et al, 2005) and between schools (eg Hadfield and Chapman, 2009), but unless they are underpinned by deep collegiality (Little, 1982) focused on learning and teaching, they cannot really be described as professional learning communities.

Leadership of and within professional learning communities

Leadership is essential to professional learning communities' success. In England, strong school leaders who support other schools' development are a core feature of the self-improving school system. Among several examples is a national network of teaching schools. Outstanding schools apply to become teaching schools, supported by an alliance of other schools and partners ${ }^{2}$. By January 2015 , 
598 teaching schools represented 487 alliances, with a goal of 600 teaching schools by March 2016 . $32 \%$ of schools are currently known to be part of a teaching school alliance (TSA). Three of teaching schools' six leadership responsibilities are research and development (R\&D), identifying and developing leadership potential, and Specialist Leaders of Education, senior and middle (teacher) leaders with particular knowledge and skills which they use to support colleagues across the alliance.

England also has a designated 'middle leader' role. This person may have responsibility for a subject, for pastoral care of students

If the self-improving system underpinned by evidence-informed teaching is to become a reality, leadership has to spread beyond senior leaders to teacher leaders who will become champions for change, evidence use and evaluation of impact, and who will act as catalysts in helping to change the system within and across enquiry-focused professional learning communities (Stoll, 2015a). While other teachers have the opportunity to apply for lead practitioner positions in schools, supporting the wider spread of teacher leadership, more informal teacher leaders are needed.

Furthering England's previous policy white paper The Importance of Teaching (DfE, 2010), the thrust has been towards developing teaching as an evidence-based profession. England's National College for Teaching and Leadership suggests that this will exist when:

All teaching practice reflects both individual teaching expertise and the best and most up-todate external evidence from systematic research.

(cited in Hammersley-Fletcher and Lewin, 2015, p933)

Schools are increasingly expected to use evidence when selecting, implementing and evaluating improvement efforts. Many schools draw on the Sutton Trust / Education Endowment Foundation (EEF) toolkit ${ }^{4}$ and John Hattie's (2012) research to identify reliable and good value interventions with demonstrable impact. Similarly, in using pupil premium funding for disadvantaged students ${ }^{5}$, schools are encouraged to attend to evidence-based approaches, and some schools encourage teachers to use evidence in the classroom (Nelson and O'Beirne, 2014). Two of us are also involved in a project for the Department of Education evaluating progress towards an evidence-based teaching system ${ }^{6}$. 


\section{Three projects}

We have been exploring these issues through our involvement in three national projects in England. Two - a middle leader knowledge exchange project with Challenge Partners, a national voluntary network of schools, and a national teaching schools network enquiry project - are completed at the time of writing. The third - Research Learning Communities, a research use randomized control trial project, is ongoing and provides the opportunity to further examine methodologies and test out findings in a pilot with potential for national scale up.

\section{Middle leaders as catalysts for improving teacher practice}

This one-year applied research project, funded as part of the Economic and Social Research Council's Knowledge Exchange Scheme ${ }^{7}$, was designed, co-facilitated and jointly evaluated by a partnership involving the London Centre for Leadership in Learning at the UCL Institute of Education (IOE) and Challenge Partners. The UCL IOE team was led by Louise Stoll and included the other authors. Challenge Partners is a collaborative group of $300+$ schools across England, focused on improving the quality of teaching and leadership in pursuit of better outcomes for its students. It provides a vehicle for schools that wish to learn from the best of their peers via effective networking, with 'hubs' (networks) established across the entire partnership ${ }^{8}$.

Reviewing the distributed leadership literature, Harris (2009) concludes that leadership distributed to teachers in 'planful ways' has a positive influence on student learning outcomes. Middle leaders teacher leaders such as heads of subject departments or subject coordinators - can be fundamental to successful school improvement and improved teacher practice in leading teaching and learning. Through their commitment to supporting peers' development and the learning of students beyond those they teach they demonstrate collective responsibility, a core characteristic of professional learning communities.

Challenge Partners' senior leaders wanted to collaborate with us in developing teacher leaders' capacity to share their expert knowledge with other middle leaders and teachers, especially in other schools, and to track their interventions' impact through to changes in teachers' practice and, ultimately, student learning, progress and development. We aimed to explore and learn about establishing an effective knowledge exchange and impact network with a group of 16 'catalyst' middle leaders (Stoll and Brown, 2015) across leading Challenge Partner schools, who would then extend this 
learning to their hub school partners, and share the outcomes of their applied project work more widely to benefit a broader range of educators. Our project questions were:

1. What do we know about effective middle leadership within and across schools that changes teachers' practice?

2. What are powerful ways to share knowledge about excellent middle leadership practice within and across schools?

3. What evidence-based tools can be designed collaboratively between Challenge Partners middle leaders and academic partners to track changes in teachers' practice as a result of middle leaders' interventions?

4. What leadership conditions in schools help develop and embed cultures of shared outstanding practice?

Research findings and best practice were shared in workshops in innovative ways. Middle leaders then used new learning to create and refine processes and tools to help them lead more effectively and track their impact, testing ideas and trialling tools in their own and other schools through face-to-face and social networking activities. They evaluated these experiences and impact on them and colleagues, and jointly developed processes to embed the notion of sharing high quality researchinformed practice between schools in their networks and for practitioners in other networks.

The methodology ensured that different partners pooled their prior research-based and practicebased knowledge, and combined these to answer the project's questions. A parallel evaluation collected baseline information and followed project activities (Stoll et al, 2015). Self-evaluation tools helped catalysts analyse change over time, and we carried out final interviews with some catalysts and headteachers and some follow-up interviews after one year. An iterative co-construction process generated answers to the research questions (Stoll et al, 2015). Seven messages (answers) were derived for each question and verified against data gathered. Final 'key messages' were then validated with Challenge Partners' colleagues who had attended workshops ${ }^{9}$. Drawing on workshop and evaluation data, these 'soundbite' messages were expanded and used to develop professional (leadership) learning resource cards (Stoll, 2015c). 
Middle leaders learnt how to lead educational change in a theory-rich way. In line with the funder's mission to focus on behaviour change, they explored the best ways to support colleagues in improving their practice. Introducing research perspectives on the nature of change itself proved highly significant. This resonated and was quickly internalized by many middle leaders, who consistently drew on it, weaving it into workshop conversations and tasks between sessions. They also reported on resulting successes, and were keen to share what they had learnt about change leadership with other middle leaders in their regional hubs and elsewhere.

From their projects with individual teachers and middle leaders in their school, and groups of teachers and middle leaders elsewhere, we concluded that middle leadership within and across schools is more likely to change teachers' practice when middle leaders understand how to lead change, read and develop their knowledge of relevant research, use this and other data to identify issues, inform changes, improve practice, and evaluate progress. This appears to give them further confidence to take initiative. The most successful middle leaders had drive and energy, stimulated meaningful, informal conversations to connect and support development, and were outward facing, networking and seeking great practice elsewhere. They role modelled, championed improvement, were constructive critics, involved others, and kept morale up. While they were clear about their vision of great teaching and learning and understood the importance of strategically planning ahead, they adapted plans to fit different colleagues' needs. They also supported and coached colleagues to experiment and develop new practice, developing a trusting, collaborative culture within their smaller professional learning teams in which colleagues felt valued.

\section{Tracking impact}

Middle leaders learnt research-informed approaches to tracking impact (eg Guskey, 2000; Earl and Katz, 2006; Timperley, 2011; Halbert and Kaser, 2011) and enabled others to do the same. They designed impact tools that they found powerful in helping stimulate and track changes in colleagues' practice and which were focused on improvements in students' learning. Impact measures were contextualized to specific situations and issues, but enquiry processes always included a baseline against which impact could be judged (Taylor and Spence-Thomas, 2015). They crafted questions which helped to open up conversations between them and colleagues, shifting the emphasis from accountability of colleagues to their professional development. Catalysts described changes in 
colleagues' practice and greater openness to change because the process helped build ownership. Follow up interviews highlighted how several were continuing to use tools in different situations, and some had influenced senior leaders to embed them within school development plans. Change in students' learning was the ultimate goal. By the project's end some were noticing changes, as one described:

I learnt how important learning conversations are, and now ensure staff have stimulating and engaging conversations about their practice. They never used to have meetings about what they were doing and how this affects the children, and now they are having these every night. As a result they now know their children well and are not afraid to have difficult conversations. For example, recently they looked at how resources were placed, realized that children weren't using resources to learn and so have been changing their resources. They are now getting improved verbal interactions with the children as a result.

The seven messages about tracking impact we derived from findings of their evidence-informed intersessional activity were that when middle leaders are working with colleagues to track impact they need to:

1. Start with the end in mind - Ensure shared understanding about the difference they want to make, by focusing on the benefit to learners and listening to their voice up front, whether this is a student or a teacher. Well-designed questions help to elicit issues.

2. Know what they're measuring - The ultimate impact is always improvements in student learning. Collecting a baseline enables tracking of progress and comparisons to be made at the end. Colleagues then can explore what has had the desired impact using different methodologies - gathering both 'hard' and soft' data.

3. Plan clear action - Informal conversations, supported by understanding great practice and knowledge of research findings, help identify appropriate interventions. Professional learning opportunities, time and space are arranged to help put plans into action. Progress is monitored.

4. Share ownership - Collaboration between middle leaders and practitioners is important, as they share the same experience. Engaging in positive, supportive and challenging dialogue, questioning and coaching, helps build a culture of trust. 
5. Plan for sustainability - The process is part of whole-school development. Big picture thinking ensures that it's not just superficial change, but is something that lasts. Attention is paid to checking that it's working and using feedback to improve the process.

6. Provide opportunities for reflection - Knowing what made the impact is central. Middle leaders and teachers need to ask themselves "have I made a difference?" and need time and space to reflect on this.

7. Treat it as an ongoing cycle - The whole process of auditing, training, developing capacity, and measuring impact repeats itself.

Figure 1 presents an impact tracking cycle based on middle leaders' presentations of their collaboratively designed tools and interview data highlighting successful elements in stimulating changed behavior of colleagues.

Figure 1: Middle leaders' impact tracking cycle: focus = colleague's practice change and pupil learning

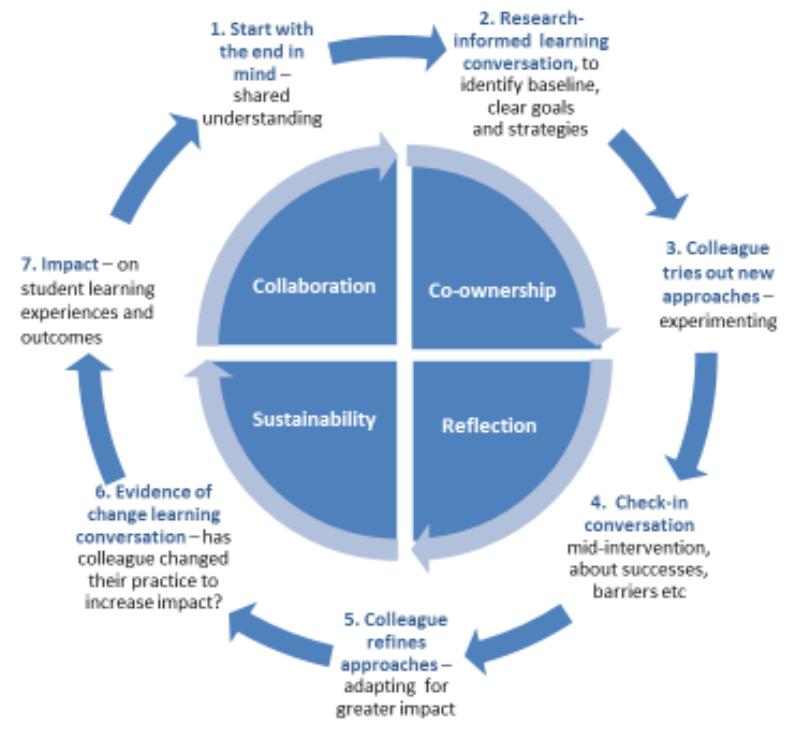

The process is intended to be collaborative and sustainable. The ongoing learning conversations help stimulate reflection and encourage co-ownership of the learning process. Introducing relevant external research helps to inform decisions about interventions or strategies to try out. A check-in conversation identifies barriers and enables refinements to be made for greater impact. A further conversation then explores the evidence of change, further data collected, and then impact on student learning experiences and outcomes is assessed. The cycle then continues. 


\section{Knowledge sharing within and across schools}

Initial interviews and end of project self-evaluations highlighted that most middle leaders' initial knowledge about tracking impact was superficial and tacit - this wasn't something they discussed in school meetings or informally with colleagues. By the end of the project, they had much deeper understanding about the theory underpinning impact tracking and experience of doing this with colleagues. Most were now sharing this knowledge within their schools and some had set up initiatives with other schools, for example through an early years network and in a secondary school network using research lesson study (Dudley, 2014).

We found that sharing knowledge about excellent middle leadership and other practice within and across schools is enhanced when middle (teacher) leaders create a culture for learning with openness to dialogue, where people can speak their minds in a safe environment, issues are explored and experimentation and acceptable risk taking is encouraged. They also need to understand others' contexts and realities through observing practices and meetings in different contexts, and careful listening so they can tailor support approaches and bring back ideas to their own school. The most successful middle leaders created opportunities to share successes and innovation, using professional learning forums, meetings, newsletters and social media to help build shared objectives around knowledge exchange, and were supported by time and resources. They also devoted attention to finding common interests and goals, involving participants in the change and distributing leadership.

\section{Teaching Schools Research and Development Themes project}

Over two-and-a-half years from 2012-2014, teaching school alliances (TSAs) across England involved in the National College for Teaching and Leadership's (NCTL) research and development (R\&D) network engaged in collaborative R\&D projects investigating three themes:

- Theme one: what makes great pedagogy?

- Theme two: what makes great professional development which leads to consistently great pedagogy?

- Theme three: how can leaders lead successful TSAs which enable the development of consistently great pedagogy? 
NCTL funded 98 teaching schools to undertake collaborative R\&D in their alliances within one theme, with one third focusing on each theme.

The project aimed to:

- support teaching schools to engage in and build their capacity for R\&D activities using evidence

- provide opportunities for training and forums for networking and sharing expertise between teaching school leaders and teachers so that they could learn from each other

- produce robust evidence to disseminate more widely

External facilitators from UCL IOE and Sheffield Hallam University were commissioned as the national research partner for themes one and two (Nelson et al, 2015a). Karen-Spence Thomas and Carol Taylor led the team, and Louise Stoll was involved, also writing an overarching report at the project's completion (Stoll, 2015b). This chapter mainly focuses on the 66 alliances involved in themes one and two. To provide structure and direction, we convened regional enquiry clusters once each school term. A key aim of these clusters was to support them to develop and embed a sustainable model for deep professional learning through a rigorous and supported R\&D methodology (Harris and Jones, 2012) elaborated with the UCL IOE's own impact framework (Earley and Porritt, 2013), based on Guskey's (2000) work on evaluating impact of professional development. The TSAs were focused on making a difference. Ultimate goals were enhanced student learning and social outcomes and many projects targeted these directly. Others focused on creating and evaluating conditions necessary to ensure the great teaching and learning experiences that would lead to that impact.

It was important to find ways to connect teachers with the research base. Schools were encouraged to engage in innovative and creative ways with bespoke literature reviews produced for each theme (Husbands and Pearce, 2012; Stoll et al, 2012b). Each review proposed 'claims' from the literature which schools used to reflect on their practices and to determine focus areas. TSAs and schools also drew on a range of other research sources and/or higher education institute (HEI) support.

These findings are based on analysis of final reports and case studies. Impact reports followed a template created by the IOE/SHU. Case studies (Nelson et al, 2015b) were written to a common structure and describe activity and findings under the R\&D methodology phases of implementation, innovation and impact. Evidence from the final reports and case studies were compared with claims from the literature reviews which formed part of the framework for the research. 
Impact on students and teachers

Importantly, many projects which targeted student learning both directly and indirectly showed a range of impacts on these students. Project evaluations identified positive effects in a range of curriculum outcomes e.g. literacy skills, mathematical problem solving, attitudes to reading, etc. Improved engagement and confidence, increased independent working, managing self-behaviour, mindfulness, and improved orientation to learning were other positive outcomes. For example, one TSA focused on using higher order thinking skills through exploratory talk. Outcomes included more evidence of children questioning each other and engaging in dialogue which involved cause and effect, predicting, seeking and verbalising patterns. Cross-school networking also had positive effects on many involved teachers and other staff, including enhanced classroom practice, increased confidence, better planning for effective assessment, and increased subject and pedagogic knowledge, with ability to articulate this clearly. Teachers reflected more and used a wider range of strategies, with greater inclusion of students in designing resources. Staff now worked more closely with colleagues, readily seeking and sharing pedagogies, engaging in improved professional dialogue, and being more involved in and enjoying R\&D. Examples also exist of improved staff morale and self-esteem.

There were also significant shifts at school level with the growth of new research, coaching or lesson study cultures. Growth in leadership capacity resulted from opportunities offered to teachers engaged in leading and working with small groups of colleagues, and positive impacts on students lead to more widespread staff confidence. One TSA's focus had been coaching to raise attainment and address transition issues. Outcomes included teacher leadership competences developed as a direct result of involvement, with success evidenced in $70 \%$ of coaches gaining senior leadership positions and $50 \%$ of coachees promoted into middle leadership following their project involvement.

\section{Teacher leaders and their roles in tracking impact}

As TSAs joined the project in three waves over the two and a half years, so the roles of those participating changed. For the first group of schools the majority of staff attending regional clusters were TSA heads or principals. By wave two, several headteachers had distributed project leadership to a senior colleague with designated responsibility for R\&D. By wave three, middle leaders and more recently qualified teachers, often loosely defined as 'research champions', had been brought on board to drive collaborative investigations within and across schools. This suggests a strategic move by 
schools over time to create capacity for R\&D by shifting its leadership from senior level through to the middle tier and even directly and more widely to classroom teachers. This distribution of leadership within and across schools as part of a collaborative enquiry process appears to be important for sustainability and capacity building. Where collaborative activity was most productive, senior leaders created a clear and compelling shared vision for the difference it would make for student learning. They then operationalized this by creating time and space for middle and teacher leaders to engage positively with each other over time. Enabling teachers to centre their enquiries in their classrooms within a common, overarching, cross-alliance theme or focus was highly motivating and effective, ensuring that teacher engagement was more likely to be sustained over time (Nelson et al, 2015a).

Teacher leaders can play a powerful role in tracking impact. Impact depends on teacher leaders having the commitment and the skills to know what difference their interventions make. Facilitators worked with their teachers to flesh out the desired impact of the investigations on student learning and outcomes. Teams then gathered baseline evidence of practice and learning against which the impact of changed practices could be evaluated. This process of individual, classroom-centred visioning proved empowering for teacher leaders, providing them with a rigorous framework with which to think deeply about and articulate their students' needs. Enquiry facilitators - often middle or teacher leaders in phase three - supported enquiry teams of teachers to analyse data and determine whether changes in teacher practices had brought about improvements in student learning. Collaborative approaches, for example research lesson study (Dudley, 2014), enabled teachers to grow in confidence and develop the criticality necessary to critique and scrutinize each other's practices.

TSAs combined 'external' knowledge from the literature reviews with their experiential, practicebased knowledge to create insights and capabilities in ways which were new for them (Nelson et al, 2015a). They rarely focused exclusively on one claim. In one TSA, blending five different research claims about effective pedagogies in projects helped deepen participants' insights and enrich their learning. Analysis following each of two cycles of lesson study showed that the process had "opened some teachers' eyes to how many children were learning to calculate without necessarily understanding the structure behind what they were doing. Using manipulatives had enabled teachers to get an insight into the pupils' understanding..." (Nelson et al, 2015a pp37-8). 


\section{$\underline{\text { Research Learning Communities project }}$}

This Education Endowment Foundation (EEF) funded project's aim has been to test a pilot designed to increase research use and improve learning outcomes among primary (elementary) school teachers at scale. Led by Chris Brown and involving two other authors, we have been developing then exploring the efficacy of an approach that has involved researchers working intensely with small groups of practitioners, many of whom are teacher leaders. These practitioners, in turn, have been charged with engaging in peer-to-peer support with a much greater number of colleagues.

EEF has a mandate to invest in proven initiatives, and stipulated the necessity for an independent evaluation of the pilot, including a randomized control trial to assess its impacts effectively ${ }^{10}$. This includes effectiveness in terms of increasing research use (the process evaluation) as well as the ability to raise outcomes for pupils in national assessments at key stage $2^{11}$. In line with this, we recruited 110 primary schools across England, with half forming Research Learning Communities (RLCs) (made up of 10 groups of 5-6 schools), and half forming the control group.

\section{Teacher leadership is fundamental to RLCS}

Teacher leadership is fundamental to RLCs. Each school engaged in RLC activity provided two leaders: a senior leader and an informal opinion leader (teacher leader). Formal leadership buy-in to research use is vital. School leaders promote the vision for and develop the culture of a research-engaged school. They also provide necessary resources and structures for sustained and meaningful research use (Leithwood et al., 2006). Their first-hand participation ensures that such activity is more likely to remain a priority. In addition, they can 'walk the talk': in demonstrating commitment and engaging in leadership for learning (Southworth, 2009), they are more likely to ensure wider school buy-in.

At the same time, if leadership is a process of influence, leadership activity can be undertaken by more than those possessing formal responsibility. Informal leaders frequently determine the fate of change initiatives, and implementing initiatives must attend to the informal day-to-day aspects of an organization (Spillane et al., 2010). Drawing on our existing experience about the importance of catalysts, in designing the project, we knew it was essential to have the right people in the room. Social Network Analysis was used to identify and map informal structures and understand the roles of social actors within these structures. Specifically, we were interested in how potential central actors teacher leaders - in favour of the idea of research-informed practice, might act as research 
'champions', circulating research knowledge within their schools. Based on this rationale, each participating primary school is represented by a senior leader (sometimes the headteacher) and a teacher leader evidence champion.

Research learning communities extends the concept of professional learning communities

Research Learning Communities (RLCS) have evolved from the literature on professional learning communities (PLCs) and networked learning communities (NLCs),. RLCs, however, were designed with the specific purpose of increasing research use in schools at scale. So their networked approach explicitly focuses on learning from and building upon existing academic knowledge to tackle key teaching and learning issues. As a result, knowledge creation activity within them necessarily has to centre on learning conversations (Earl and Timperley, 2009) between explicated practitioner knowledge and academic knowledge, with experience and external knowledge/theory bought to the fore and made equal partner with practitioner knowledge (Brown and Rogers, 2015; Stoll and Brown, 2015). In addition, to achieve expertise in evidence use among large numbers of practitioners, RLC activity takes place within a double helix of activity. This ensures that first, newly created knowledge and solutions that build on such knowledge can be engaged with practically and so help RLC participants build an understanding as to when and how it is appropriate to use them (ie. to develop their expertise). Second RLC participants have the opportunity to build capacity to engage with and share their expertise with others, who can then also begin to practise what they have learned through a subsequent structured series of activities within their individual schools. This has the added benefit of RLC participants, those who are 'one step ahead' in terms of their understanding and ideas, being able to gain further understanding through modelling and for others to be able to learn through interaction with their peers (Penuel et al, 2012).

The process draws on and extends the methods and findings of the two previous projects. We work with the pairs of leaders in their ten RLCs, who came together for a one-day work shop four times a year in the first year supported by UCL Institute of Education researcher-facilitators (Coburn et al., 2013), team members conversant with using evidence and able to engage participants in learning conversations. Workshops focus on a specific issue of importance identified by schools and agreed on in advance and introduce research evidence that investigates 'what seems to work' in relation to these issues. Researcher-facilitators engage in learning conversation exercises to enable participants to:

- engage interactively with both research and their own and colleagues' tacit practice-based 
knowledge;

- conceive of specific enquiries (in terms of issues) that apply to their school and develop, trial and embed evidence informed solutions to tackle these; and

- evaluate the impact of these approaches employing a variety of perspectives.

Cycles of enquiry are central to RLCs activity. After analyzing approaches to developing cycles of enquiry (eg Halbert and Kaser, 2011; Timperley, 2011; Harris and Jones, 2012; Schildkamp and Ehren, 2013; Coburn et al., 2013), and considering RLC project requirements to increase dissemination and research use within schools, the RLC's cycle of enquiry principles were developed.

1. The enquiry has to be grounded within the RLC's overall focus area.

2. The enquiry has to be data informed: it needs to address a real issue faced by the school, not one based on perception.

3. Because the enquiry is data informed, baseline data can and should be gathered so that progress can be ascertained later.

4. Expected outcomes/the resulting transformative 'vision' should be determined so that participants (and those in their 'home' school) understand what is expected of them.

5. Research evidence needs to be employed as part of solutions developed to address the issue of inquiry.

6. All activity within the enquiry cycle must involve meaningful interaction between those participating in the RLC and members of their 'home' school.

7. Impact of evidence-informed solutions must be evaluated to ascertain their use value.

8. Results of the evaluation should be shared (with other RLC participants and back in their 'home' schools).

9. Following evaluation and sharing, solutions should be collaboratively refined, radically changed or removed as appropriate.

Sharing with RLC colleagues in other schools has been an important feature, although the first year emphasis was on within-school enquiry. As year two develops, researcher-facilitators will offer resources and support around networked enquiry. 


\section{Impactful teacher leadership of change and improvement within and across professional learning communities}

Through the opportunity to collaboratively develop, lead and analyse these projects and their impacts thus far, our thinking continues to evolve. The RLCs project is enabling us to continue testing these ideas and trialling others in the service of increasing impact. Meanwhile, we conclude with four messages about impactful teacher leadership of change and improvement within and across professional learning communities.

Teacher leaders are more likely to have an impact within and across PLCS when supported by impactoriented collaborative enquiry within a culture of trusting relationships

Our experience suggests that using data and external research evidence within an impact-oriented enquiry framework can lead to significant impact for students and for teachers' practice. In ongoing work, we are continuing to refine and extend our enquiry cycle principles.

In line with other work on professional learning communities (eg Louis, 2008), our projects highlight the need for trusting relationships as a basis for impactful action. In using impact tracking tools, knowledge exchange project participants concluded that stimulating meaningful conversations helped to build the kind of relationship that enabled them to work successfully with colleagues in other schools:

“with somebody you don't know they may not trust you but you have the opportunity to build that trust through the conversation you have. Trust does need to be built with the person you're working with in order for it to succeed". (Middle leader reporting on tool use)

The RLCs project social network analysis survey also found that higher levels of trust are likely to lead to more frequent (and so useful) ties that result in a variety of reciprocal efforts, including collaboration, learning, complex information sharing and problem solving, shared decision making, and coordinated action: actions essential to development of new and effective practice informed by research and evidence. Consequently, high trust levels appear to lead to teachers perceiving that they are encouraged to use research and that their school's improvement is being driven by research.

Teacher leaders need support of senior leaders to become evidence-informed impact catalysts 
Senior leaders played a significant role in teacher leaders' ability to develop knowledge and skills around using evidence to increase impact. In particular, headteachers' commitment to evidenceinformed practice is essential. This includes creating a culture in which this is valued and expected, modelling this in their practice, and ensuring that necessary structures provide time, space, resources and other support. The national R\&D project and RLCs project both involved senior leaders as active participants, while the knowledge exchange project was sponsored by headteachers. All cases, however, included examples where teacher leaders did not receive necessary support and backing. Schools are beset by competing priorities, and senior leaders who do not see wider benefits of projects in which one or a few staff may be involved may not pay considerable attention. This was a key reason why the RLCS project involved both a senior leader and an opinion former. Nonetheless, even if headteachers (principals) are convinced about the benefits of evidence-informed practice, persuading them to make changes when other interventions are in full swing can be difficult.

Teacher leaders need external support in their own professional learning communities to deepen evidence-informed practice and knowledge exchange

Our evidence demonstrates that it isn't sufficient to model excellent classroom practice. Teacher leaders need to know how to work alongside others within their school and elsewhere over time to articulate and share their knowledge about what makes great pedagogy in systematic ways. They need to learn powerful forms of enquiry. This was not included in many teachers' initial teacher training or they were trained sufficiently long ago that this is not part of their everyday repertoire. To a lesser or greater degree, within and across schools, teacher leaders need to be able to: facilitate professional learning; access, critique and share the 'external' knowledge base; trial new strategies and evaluate their impact; bring colleagues into investigations and build teams; evaluate the impact of changed practice on student learning and achievement; and share findings in accessible and sustainable ways.

Reflecting on the national R\&D themes project, Nelson et al (2015a, p 59) also caution: 'Mobilising learning from school-led collaborative enquiry to influence wider staff across a school or alliance is challenging and often neglected'. Leaders used various strategies to share project outcomes and learning with colleagues within their schools and in other schools. Many approaches focused on raising awareness, but did not always sufficiently engage colleagues to 'jump on board' and try out project strategies themselves. Some, however, showed a strong learning orientation in their approach to mobilising their new knowledge. In particular, those that used a form of collaborative professional 
learning or development of enquiry skills within or as the focus for their projects took this forward as a mechanism to engage more colleagues.

All of these skills need systematic and structured development in supportive professional learning communities with opportunities to apply and reflect on learning between sessions. Teacher leaders gained considerably from participating in a group of colleagues focused on the same goals. Significant parts of workshops and meetings were devoted to colleagues acting as each other's critical friends, supporting and challenging, asking probing questions. Through this, they learnt about each other's successes, difficulties and how to deal with blockages. Externally facilitated sessions need to be designed to build capacity for sustainability of the approach, ensuring that participants and their schools can continue to use evidence effectively after projects end.

\section{References}

Bolam, R., McMahon, A., Stoll, L., Thomas, S. and Wallace, M. with Greenwood, A., Hawkey, K., Ingram, M., Atkinson, A. and Smith, M. (2005) Creating and Sustaining Effective Professional Learning Communities. Research Report 637. London DfES and University of Bristol.

Brown, C., Daly, A. and Liou, Y-H. (2016) Improving trust, improving schools: findings from a social network analysis of 43 primary schools in England, Journal of Professional Capital \& Community, early online access.

Brown, C. and Rogers, S. (2015) Knowledge creation as an approach to facilitating evidence-informed practice: examining ways to measure the success of using this method with early years practitioners in Camden (London), Journal of Educational Change, 16 (1): 79-99.

Coburn, C., Penuel, W. and Geil, K. (2013) Research-Practice Partnerships: A Strategy for Leveraging Research for Educational Improvement in School Districts. New York, NY: William T. Grant Foundation.

DfE (2010) The Importance of Teaching White Paper. London: Department for Education.

DfEE (1997) White Paper: Excellence in Schools. London: Her Majesty's Stationery Office. 
DfES (2005) White Paper: High Standards, Better Schools for All. London: Department for Education and Skills.

Dudley, P. (2014) Lesson Study: Professional Learning for our Time. London: Routledge.

Earl, L. and Katz, S. (2006). Leading schools in a data-rich world: Harnessing data for school improvement, Thousand Oaks, CA: Corwin.

Earl, L. and Timperley, H. (2008) Professional Learning Conversations: Challenges in Using Evidence for Improvement, Dordrecht: Springer.

Earley, P. and Porritt, V. (2014) Evaluating the impact of professional development: the need for a student-focused approach, Professional Development in Education, 40 (1): 112-129.

Guskey, T. (2000) Evaluating Professional Development. Thousand Oaks, CA: Corwin.

Hadfield, M. and Chapman, C. (2009) Leading School-based Networks. London: Routledge.

Halbert, J. and Kaser, L. (2013) Spirals of Inquiry for Equity and Quality. Vancouver, BC: BCPVPA.

Hammersley-Fletcher, L. and Lewin, C. (2015) Evidence-based teaching: advancing capability and capacity for enquiry in schools. Interim Report. Autumn 2015. NCTL.

Hargreaves, D.H. (2010) Creating a self-improving school system. Nottingham: NCSL.

Harris, A. (2009) Distributed leadership: what we know, in A. Harris (ed) Distributed Leadership: Different Perspectives. Dordrecht: Springer.

Harris, A. and Jones, M. (2012) Connect to Learn: Learn to Connect, Professional Development Today, 14 (4): 13-19.

Hattie, J. (2012) Visible Learning for Teachers: Maximizing Impact on Learning. London: Routledge. 
Husbands, C. and Pearce, J. (2012) What makes great pedagogy? Nine claims from research. Nottingham, NCSL.

Istance, D. and Vincent-Lancran, with Van Damme, D., Schleicher, A. and Weatherby, K. (2012) in A. Schleicher (Ed) Preparing Teachers and Developing School Leaders for the 21st Century: Lessons from Around the World. Paris, OECD

Leithwood, K., Day, C., Sammons, P., Harris, A. and Hopkins, D (2006) Successful school leadership: what it is and how it influences student learning. Research Report 800. London: DfES.

Little, J. W. (1982) Norms of collegiality and experimentation: workplace_conditions of school success, American Educational Research Journal, 19 (3): 325-340.

Louis, K. S. (2008) Trust and improvement in schools, Journal of Educational Change, 8 (1): 1-24.

Louis, K S, Kruse, S D and Associates (1995) Professionalism and Community: Perspectives on Reforming Urban Schools Thousand Oaks, CA: Corwin.

Mourshed, M., Chijioe, C. and Barber, M. (2010) How the World's Most Improved School Systems Keep Getting Better. London: McKinsey \& Company.

Nelson and O'Beirne, (2014) Using Evidence in the Classroom: What Works and Why. Slough, NFER.

Nelson, R., Spence-Thomas, K. and Taylor, C. (2015a) What makes great pedagogy and great professional development: final report. Nottingham, NCTL.

Nelson, R., Spence-Thomas, K. and Taylor, C. (2015b) What makes great pedagogy and great professional development: case studies. Nottingham, NCTL.

OECD (2016) Supporting Teacher professionalism: Insights from TALIS 2013. Paris: OECD Publishing.

OECD (2013) Fostering learning communities among teachers. Teaching in Focus. O4 (June). Paris: OECD 
Penuel, W., Sun, M., Frank, K. and Gallagher, A. (2012) Using social network analysis to study how interactions can augment teacher learning from external professional development, American Journal of Education, 119 (1): 103-136.

Schildkamp, K. and Ehren, M.C.M. (2013) From "intuition"- to "data"-driven decision making in Dutch secondary schools? In K. Schildkamp, M.K. Lai, and L. Earl (eds) Data-based Decision Making in Education: Challenges and Opportunities. Dordrecht: Springer.

Schleicher, A. (2015) Schools for 21st-Century Learners: Strong Leaders, Confident Teachers, Innovative Approaches, International Summit on the Teaching Profession, Paris: OECD Publishing.

Southworth, G. (2009) Learning centred leadership, in B. Davies (ed) The Essentials of School Leadership ( $2^{\text {nd }}$ edn), London: Sage.

Spillane, J., Healey, K. and Kim, C. (2010) Leading and managing instruction: formal and informal aspects of elementary school organization, in A. Daly (ed) Social Network Theory and Educational Change, Cambridge, MA: Harvard Education Press.

Stoll, L. (2015a) Using evidence, learning and the role of professional learning communities, in C. Brown (ed) Leading the use of Research \& Evidence in schools, London: IOE Press.

Stoll, L. (2015b) Three greats for a self-improving school system - pedagogy, professional development and leadership: Teaching schools R\&D network national themes project 2012-14. Nottingham: NCTL.

Stoll, L. (2015c) How Do We Create and Exchange Knowledge For Systemic Change? ICSEI Monograph Series: Issue 6. International Congress for School Effectiveness and Improvement

Stoll, L. and Brown, C. (2015) Middle leaders as catalysts for evidence-informed change, in C. Brown (ed) Leading the use of Research \& Evidence in schools, London: IOE Press.

Stoll, L., Brown, C., Spence-Thomas, K. and Taylor, C. (2015) Perspectives on teacher leadership for evidence-informed improvement in England, Leading and Managing, 21 (2): 76-91. 
Stoll, L., Halbert, J. and Kaser, L. (2012a) Deepening learning in school-to-school networks, in C. Day (ed) The Routledge International Handbook of Teacher and School Development. London: Routledge.

Stoll, L., Harris, A. and Handscomb, G. (2012b) Great professional development which leads to great pedagogy: nine claims from research. Nottingham, NCSL.

Taylor, C. and Spence-Thomas, K. (2015), Understanding impact and the cycle of enquiry, in Brown, C. (ed) Leading the use of research and evidence in schools, (London, IOE Press).

Timperley, H. (2011) Realizing the Power of Professional Learning. Maidenhead: Open University Press.

\footnotetext{
${ }^{1}$ England's external inspection agency.

${ }^{2}$ https://www.gov.uk/government/policies/improving-the-quality-of-teaching-and-leadership/supportingpages/teaching-schools gov.uk website

${ }^{3}$ NCTL EBT ACCESs project brief, 2014.

${ }^{4}$ http://educationendowmentfoundation.org.uk/toolkit/Education endowment website

${ }^{5}$ https://www.gov.uk/pupil-premium-information-for-schools-and-alternative-provision-settings gov.uk website

${ }^{6}$ A collaborative project between colleagues at Sheffield Hallam University, the UCL Institute of Education, and Durham University.

7 ESRC Knowledge Exchange Opportunities Scheme R\&D project - Grant: ES/I002043/1

${ }^{8}$ See: http://challengepartners.org

${ }^{9}$ http://www.lcll.org.uk/uploads/2/1/4/7/21470046/ml change catalyst.pdf

${ }^{10}$ Full detail on the evaluation including its methodology can be found via:

https://educationendowmentfoundation.org.uk/projects/research-learning-communities/and results will be available in 2016

${ }^{11}$ Key Stage 1 refers to 5-7 year olds, Key Stage 2 to 7-11 year olds (KS1 and KS2 are primary stages), Key Stage 3 to 11-14 year olds, Key Stage 4 to preparation for GCSE examinations, and KS5 to preparation for A levels.
} 